\title{
SYSTEMIC ANTIBIOTICS VERSUS TOPICAL TREATMENTS FOR CRHONIC DISCHARGING EARS WITH UNDERLYING EARDRUM PERFORATIONS
}

\author{
MASUM SHIA ${ }^{1}$, FAKIR MAY ${ }^{2}$
}

\begin{abstract}
:
Context: Chronic suppurative otitis media (CSOM) is a common cause of preventable hearing impairment worldwide, particularly in low and middle-income countries. Untreated CSOM may result in permanent hearing loss, which in turn, may result in speech and language delays or permanent learning disabilities, as well as behavioural problem. Of the treatment options, the efficacy of using only topical antibiotics and combination of systemic antibiotics and topical antibiotics are most disputable. The present study was undertaken to investigate the role of adjuvant systemic antibiotics in the treatment CSOM.
\end{abstract}

Methods: A randomized clinical trial was carried out on children with chronic suppurative otitis media at the ENT outpatient department of Dhaka Shishu Hospital from January to December 2009. Any patient presenting with a stage of ear disease in which there is chronic infection of the middle ear cleft, a non-intact tympanic membrane and a history of discharge for at least two weeks was considered as a case. A total of 112 cases of chronic suppurative otitis media were consecutively enrolled in the study. Of them, 72 completed $3^{\text {rd }}$ follow up visit and hence, considered evaluable.

Results: The results of the study demonstrated that the study groups were almost identical in terms of age, sex, socioeconomic class and residence. The peak age incidence of chronic suppurative otitis media was found between 4-6 years (around 75\%). In both the groups, the patients were predominantly male, belonged to poor and lower middle class families and slum dwellers. No significant difference was observed between the study groups in terms of primary and secondary outcome as well as the complications encountered by the patients. Patients of who received combined therapy, 70\% of them showed resolution of otorrhoea by 2 weeks and 95\% by 3 weeks, which in the patients of topical antibiotics alone was 50\% and 87.5\% respectively. The trial did not show any adverse event except tinnitus complained by a few patients in both groups.

Conclusion: Topical quinolone antibiotics (ciprofloxacin) are equally effective as topical plus oral antibiotics (ciprofloxacin) for resolution of otorrhoea from uncomplicated CSOM. However, for faster resolution of otorrhoea, a short course systemic antibiotic can be added.

Key words: Chronic suppurative otitis media (CSOM), topical antibiotics, topical plus systemic antibiotics, primary outcome, secondary outcome.

J Dhaka Med Coll. 2010; 19(2) : 86-90.

\section{Introduction:}

Chronically discharging ears associated with underlying persistent eardrum perforations (chronic suppurative otitis media, CSOM) are a common cause of preventable hearing impairment worldwide, particularly in low and middle-income countries. ${ }^{1,2}$ Reliable data on prevalence of CSOM are rare. However, a study conducted in Kenyan school children estimated a prevalence of $1.1 \%^{3}$ and a review of school and community-based studies reported prevalence between $0.4 \%$ and $6.1 \%$ in low and middle-income countries respectively. ${ }^{4} \mathrm{CSOM}$ usually occurs in the first five years of life although it often persists into adulthood. Perforations and infection can be unilateral or bilateral. The causes/factors are inadequate treatment of acute otitis media, a recurrent episode of acute otitis media, poor access to medical care, poor socioeconomic conditions, seasonal influence, overcrowding, lack of breastfeeding, poor nutrition or hygiene and

1. Dr. SHIA Masum, Consultant, ENT, Dhaka Shishu Hospital, Sher-E-Bangla Nagar, Dhaka.

2. Dr. Md. Abu Yousuf Fakir, Assisstant Professor, ENT, Dhaka Medical College, Dhaka.

Correspondence: Dr. SHIA Masum, Consultant, ENT, Dhaka Shishu Hospital, Sher-E-Bangla Nagar, Dhaka, Cell Phone: +8801711141543, Email: shmasum_ent@yahoo.com 
host factors such as altered immunity and underlying diseases, frequent upper respiratory tract infections, early onset and family history of otitis media. ${ }^{5,6}$

Hearing impairment is the most frequent effect of CSOM. A school survey in Kenya reported $63 \%$ of ears with CSOM had more than 30 decibels hearing loss, compared to only $3.4 \%$ of ears without outer or middle ear pathology. ${ }^{3}$ Hearing impairment due to CSOM usually improves as the disease resolves. However, untreated CSOM may result in permanent hearing loss due to damage to the ossicles, which transmit sound vibrations from the eardrum to the cochlea. Because otitis media occurs mostly in children during pre-school years (the most dynamic phase of speech and language development), there is a concern about associated hearing deficit, which may result in speech and language delays or permanent learning disabilities, as well as behavioural problem. ${ }^{7}$ In addition to hearing impairment, complications of otitis media can often result in death or severe disability, especially in low-income countries ${ }^{8}$ like Bangladesh.

The aims of treatment were to stop the discharge (and to eradicate infection), to heal the tympanic membrane, improve hearing, prevent the common problems of recurrent or new infections, and to prevent potentially lifethreatening complications. Treatment options for uncomplicated CSOM include dry mopping, ear wicking, gentle syringing, or suctioning, to clean the ear discharge, systemic antibiotics and topical treatment with either antiseptics or antibiotics (sometimes with steroids). A report of a WHO/CIBA Foundation Workshop held in 1996, recommends administration of topical (and/or systemic) antibiotics as well as dry mopping/wicking, since wicking alone is felt to be ineffective. ${ }^{2,9}$ However, concern exists regarding the ability of antibiotics to penetrate the middle ear and mastoid cavities as well as their activity against the causative bacteria (usually gram negative) possible ototoxic effect (by damaging the hair cells in the basal turn of the cochlea), particularly where the eardrum is not intact. For this reason, systemic treatments are still often recommended and used in preference over topical antibiotics, where the eardrum is not intact. Sometimes systemic and topical antibiotics are given simultaneously, when topical antibiotics may be enough to resolute otorrhoea and heal the eardrum. The present study was conducted to compare the outcome of combined systemic and topical antibiotics and topical antibiotics only for chronic discharging ears with an underlying eardrum perforation (CSOM) in paediatric age group.

\section{Methods:}

A randomized clinical trial was carried out at the ENT utpatient department of Dhaka Shishu Hospital from January 2009 to December 2009. Children, from 1 month to 12 years, presenting with a stage of ear disease in which there is chronic infection of the middle ear cleft, a non-intact tympanic membrane (i.e. perforated eardrum) and discharge for at least the preceding two weeks were considered as study population. ${ }^{2}$ A total of 112 cases of chronic suppurative otitis media were consecutively enrolled in the study. The patients were then randomly assigned to either combined systemic and topical antibiotics group or topical antibiotics only group. Topical group received only topical ciprofloxacin (at $0.5 \%$ and $0.1 \%$ strengths), while combined treatment group received topical and oral ciprofloxacin $(10 \mathrm{mg} / \mathrm{kg} /$ day in 2 divided doses). Prior to starting the assigned treatment, dry mopping was done in every patient. Following treatment, patients were followed up at the end of $2^{\text {nd }}, 3^{\text {rd }}$ and $4^{\text {th }}$ week. The patients who completed all the three follow up visits were considered to be evaluated $(n=72)$. The primary outcome measure was resolution of CSOM within 2 to 4 weeks, while the secondary outcome measures were healing of perforated eardrum at 2 to 4 weeks of treatment. The treatment safety was judged in terms of complications like hearing loss, tinnitus and adverse events requiring hospitalization. The test statistics used to analyze the data were Chi-square $\left(\mathrm{c}^{2}\right)$ or Fisher's Exact Probability Test and level significance was set at 0.05 . 


\section{Results:}

Age distribution of the patients demonstrates that in both groups the highest accumulation of cases was found between 4-6 years and the lowest frequency in 6-8 years. The mean ages of the patients of topical antibiotics group was slightly higher than that of combined topical and systemic antibiotics groups $(3.5 \pm 1.5$ and $2.9 \pm 1.6$ years, $\mathrm{p}=0.167)$. Sex distribution was almost identical between the groups with male predominance $(p=0.560)$. Patients of either group predominantly belonged to poor and lower middle class with no significant difference between the groups $(p=0.199)$. In terms of residence as well there was no significant difference between the groups with preponderance of slum dwellers $(\mathrm{p}=0.472)$ (TableI). None of the patients in topical antibiotics group had conductive deafness before intervention, while 2 cases $(5 \%)$ in the combined treatment group had such problem (Fig. 1).

\section{Table-I}

Comparison of demographic characteristics between two groups

\begin{tabular}{|c|c|c|c|}
\hline \multirow{2}{*}{$\begin{array}{l}\text { Demographic } \\
\text { variables }\end{array}$} & \multicolumn{2}{|c|}{ Group } & \multirow{2}{*}{$\mathrm{P}$ value } \\
\hline & $\begin{array}{l}\text { Topical } \\
(\mathrm{n}=32)\end{array}$ & $\begin{array}{l}\text { Topical plus } \\
\text { Systemic } \\
(\mathrm{n}=40)\end{array}$ & \\
\hline \multicolumn{4}{|l|}{ Age $^{*}$ (years) } \\
\hline $1-2$ & $5(15.6)$ & $10(25.0)$ & \\
\hline $2-4$ & $12(37.5)$ & $13(32.5)$ & \\
\hline $4-6$ & $14(43.8)$ & $15(37.5)$ & \\
\hline $6-8$ & $1(3.1)$ & $2(5.0)$ & \\
\hline Mean $\pm \mathrm{SD}$ & $3.5 \pm 1.5$ & $2.9 \pm 1.6$ & 0.167 \\
\hline \multicolumn{4}{|l|}{$\operatorname{Sex}^{\#}$} \\
\hline Male & $19(59.4)$ & $21(52.5)$ & 0.560 \\
\hline Female & 13(40.6) & 19(47.5) & \\
\hline \multicolumn{4}{|l|}{$\begin{array}{l}\text { Socioeconomic } \\
\text { condition }^{\#}\end{array}$} \\
\hline Poor & $13(40.6)$ & $23(57.5)$ & \\
\hline Lowe middle class & $16(50.0)$ & $12(30.0)$ & 0.199 \\
\hline Middle class & $1(3.1)$ & $4(10.0)$ & \\
\hline Upper middle class & $2(6.2)$ & $1(2.5)$ & \\
\hline \multicolumn{4}{|l|}{ Residence $^{\#}$} \\
\hline Rural & $12(37.4)$ & $13(32.5)$ & \\
\hline Urban & $6(18.8)$ & $12(30.0)$ & 0.472 \\
\hline Slum & $14(43.8)$ & $15(37.5)$ & \\
\hline
\end{tabular}

Figures in the parenthesis denote corresponding percentage.

\# Analyses were done by using Chi-square test.

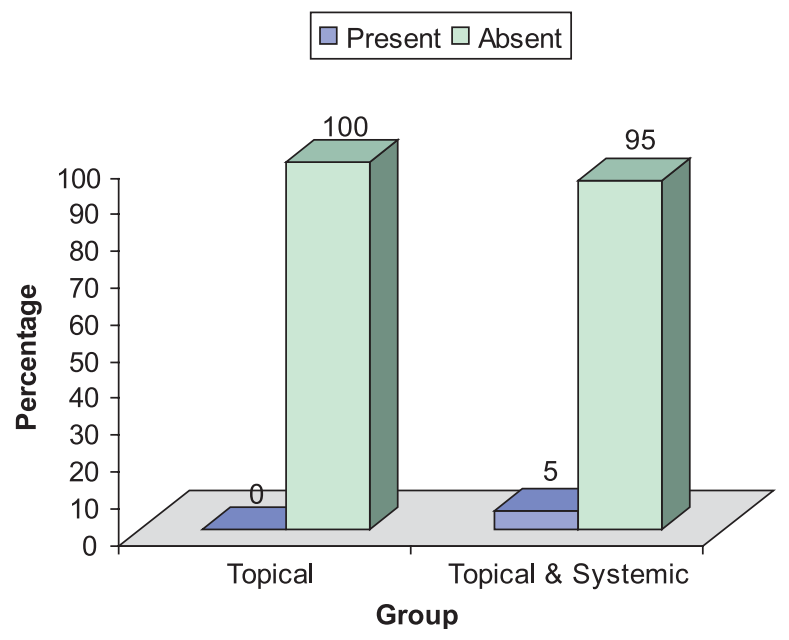

Fig. 1: Distribution of patients by presence of conductive deafness.

Two weeks after intervention, a significantly higher proportion of patients in the combined topical \& systemic antibiotics group (70\%) exhibited complete resolution of otorrhoea as opposed to $50 \%$ in the topical antibiotics group alone ( $\mathrm{p}=0.086)$ (Table-II). The rest of the patients of respective groups were examined for resolution of otorrhoea after 3 weeks of intervention. Of the 16 patients in the former group and 12 patients in the later group, $12(75 \%)$ and $10(83.3 \%)$ respectively exhibited complete resolution of otorrhoea ( $\mathrm{p}=0.479)$ (Table-III). Of the remaining 4 patients in the former and 2 patients in the latter group 3 and 1 patients respectively experienced complete resolution leaving 1 patient in each group with discharging ears. More than $97 \%$ of the combined group and $90.6 \%$ of the topical group have had healing of ear-drum by the end of 3 weeks following intervention (table IV). Of the remaining 3 patients in the topical group, 2 further showed healing of eardrum. However, after 4 weeks of treatment, 2 patients in each group exhibited reappearance of discharge. None of the complications except tinnitus was complained by $2(6.3 \%)$ and $3(7.5 \%)$ patients of topical and combined topical \& systemic antibiotics groups respectively (Fig.2). 
Table-II

Comparison of resolution of otorrhoea 2 weeks after intervention

\begin{tabular}{cccc}
\hline Resolution of otorrhoea & \multicolumn{2}{c}{ Group } & P value \\
\cline { 2 - 4 } & $\begin{array}{ccc}\text { Topical } \\
(\mathrm{n}=32)\end{array}$ & $\begin{array}{r}\text { Topical \& Systemic } \\
(\mathrm{n}=40)\end{array}$ & \\
\hline Yes & $16(50.0)$ & $28(70.0)$ & 0.086 \\
No & $16(50.0)$ & $12(30.0)$ & \\
\hline
\end{tabular}

Figures in the parenthesis denote corresponding percentage.

\# Analysis was done by using Chi-square $(\div 2)$ test.

Table-III

Comparison of resolution of otorrhoea 3 weeks after intervention

\begin{tabular}{cccc}
\hline Resolution of otorrhoea & \multicolumn{2}{c}{ Group } & P value \\
\cline { 2 - 4 } & Topical & Topical plus Systemic & \\
& $(\mathrm{n}=16)$ & $(\mathrm{n}=12)$ & \\
\hline Yes & $12(75.0)$ & $10(83.3)$ & 0.479 \\
No & $4(25.0)$ & $2(16.7)$ & \\
\hline
\end{tabular}

Figures in the parenthesis denote corresponding percentage.

\# Data were analysed using Fisher's Exact Test.

Table-IV

Healing of eardrum 3 weeks after intervention

\begin{tabular}{cccc}
\hline Healing of eardrum & \multicolumn{2}{c}{ Group } & P value \\
\cline { 2 - 4 } & Topical & Topical plus Systemic & \\
$(\mathrm{n}=32)$ & $(\mathrm{n}=40)$ & \\
\hline Yes & $29(90.6)$ & $39(97.5)$ & 0.083 \\
No & $3(9.4)$ & $1(2.5)$ & \\
\hline
\end{tabular}

Figures in the parenthesis denote corresponding percentage.

\# Data were analysed using Fisher's Exact Test.

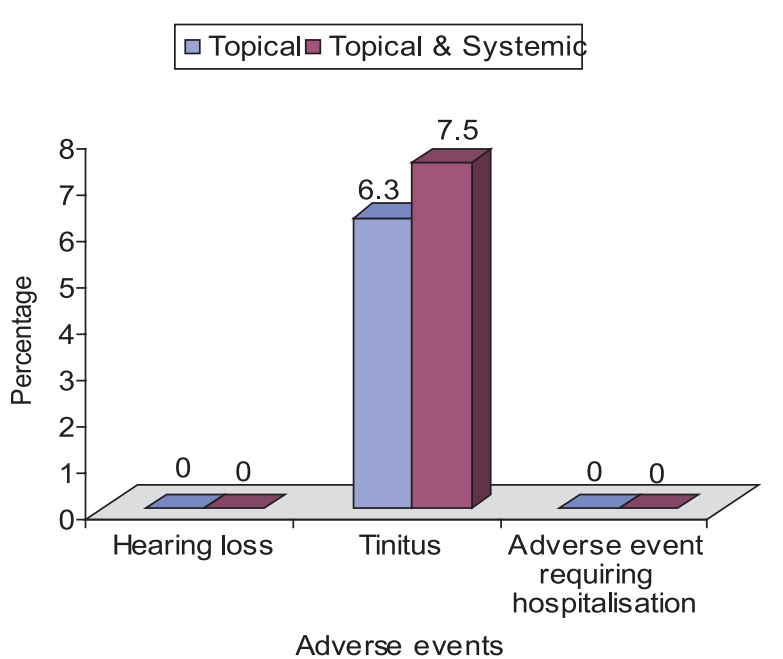

Fig. 2: Distribution of patients by adverse events

\section{Discussion:}

The findings of the study demonstrated that the study groups were almost identical in terms of age, sex, socioeconomic class and residence. The peak age incidence of chronic suppurative otitis media was found lie between 4-6 years (around 75\%). In both the groups, the patients were predominantly male, belonged to poor and lower middle class families and slum dwellers. No significant difference was observed between the study groups in terms of primary and secondary outcome as well as the complications encountered by the patients. Patients of who received combined therapy, $70 \%$ of them showed resolution of otorrhoea by the 2 weeks and 95\% by 3 weeks, which in the patients of topical antibiotics alone was $50 \%$ and $87.5 \%$ 
respectively. These findings suggest that though the final outcomes of the two treatment modalities are the same, the patients receiving combined topical and systemic antibiotics experience resolution of otorrhoea and healing of ear-drum somewhat earlier than those who receive topical antibiotics alone.

deMigue ${ }^{10}$ included two treatment groups assessing topical ciprofloxacin alone (at $0.2 \%$ and $0.5 \%$ strengths) for comparison with the treatment group receiving topical plus oral ciprofloxacin. Aural toileting that is, cleaning the ears by aspiration was done before starting the treatment. Outcome evaluated 2 weeks after starting treatment did not show any additional benefit in favour of treatment group receiving topical plus oral ciprofloxacin favouring the findings of the present study.

The trial did not show any adverse event except tinnitus complained by a few patients in either group. Similar trials that discuss safety, supported a good profile for the topical treatments assessed; one trial also reported fewer local effects for quinolone antibiotic than for antiseptic in alcohol. ${ }^{11}$

\section{Conclusion:}

Topical quinolone antibiotics (ciprofloxacin) are equally effective as topical plus oral ciprofloxacin for resolution of otorrhoea from uncomplicated CSOM. However, for faster resolution of otorrhoea a short course systemic antibiotic of quinolone group can be added.

\section{References:}

1. McPherson B, Swart SM. Childhood hearing loss in sub-Saharan Africa: a review and recommendations. Int J Pediatr Otorhinolaryngol. 1997; 40(1): 1-18.

2. World Health Organization. Prevention of hearing impairment from chronic otitis media. Report of a
WHO/CIBA Foundation Workshop, held at The CIBA Foundation, London, UK, 19-21 November, 1996. Available at: http://www.who.int/pbd/ deafness/en/chronicÿotitisÿmedia.pdf [accessed on December 31, 2008].

3. Hatcher J, Smith A, Mackenzie I, Thompson S, Bal I, Macharia I, et al. A prevalence study of ear problems in school children in Kiambu district, Kenya, May 1992. Int J Pediatr Otorhinolaryngol. 1995; 33(3): 197-205.

4. Berman S. Otitis media in developing countries. Pediatrics. 1995; 96(1): 126-31.

5. Barnett ED, Klein JO, Pelton SI, Luginbuhl LM. Otitis media in children born to human immunodeficiency virus-infected mothers. Pediatr Infect Dis J. 1992; 11(5): 360-4.

6. Singh A, Georgalas C, Patel N, Papesch M. ENT presentations in children with HIV infection. Clin Otolaryngol Allied Sci. 2003; 28(3): 240-3.

7. Klein JO. The burden of otitis media. Vaccine. 2001; 19(Suppl.1): S2-8.

8. World Health Organization. Report of the international workshop on primary ear and hearing care, Cape Town, South Africa, 12-14 March, 1998. Available at: http://www.who.int/ pbd/deafness / activities / en / capetownÿ finalÿreport.pdf [accessed on December 31, 2008].

9. Smith AW, Hatcher J, Mackenzie IJ, Thompson S, Bal I, Macharia I, et al. Randomised controlled trial of treatment of chronic suppurative otitis media in Kenyan school children. Lancet. 1996; 348(9035): 1128-33.

10. deMiguel Martinez I, Vasallo Morillas JR, Ramos Macias A. Antimicrobial therapy in chronic suppurative otitis media. Acta Otorrinolaringol Espanola [Article in Spanish] [Abstract]. 1999; 50(1): 15-9.

11. Macfadyen CA, Acuin JM, Gamble C. Cochrane review: Systemic antibiotics versus topical treatments for chronically discharging ears with underlying eardrum perforations. Evidence-Based Child health: A Cochrane Review Journal. 2007; 2(2): 611-90. 